\title{
FILOSOFIA E LITERATURA NO DISCURSO DE FOUCAULT (A ANÁLISE DE DOM QUIXOTE DE CERVANTES)
}

\author{
Augusto Bach ${ }^{1}$ \\ Universidade Estadual do Centro-Oeste (UNICENTRO) \\ (iD) https://orcid.org/0000-0003-2137-5787
}

\section{RESUMO:}

Neste artigo apresentamos a discussão arqueológica de Foucault sobre a história dos saberes e sua relação com a literatura. Com tal fito, a investigação se debruça acerca da concepção de história operada em As Palavras e as Coisas e as novidades trazidas por ela. Também investigamos a questão literária como elemento crucial para a compreensão de seu empreendimento intelectual.

PALAVRAS-CHAVE: Foucault; História, Arqueologia; Literatura.

\section{PHILOSOPHY AND LITERATURE IN FOUCAULT'S SPEECH (THE ANALYSIS OF DON QUIXOTE OF CERVANTES)}

\begin{abstract}
:
In this paper we intend to discuss Foucault's archeology and its intrinsic relationship with literature. In order to do so, our approach is twofold: analyse firtly the kind os history Foucault is operating in his classic The Order of Things and highlight the archeological point of view. Secondly, and henceforth, establish its association with the literary discourse and the consequences it brings about.
\end{abstract}

KEYWORDS: Foucault; History; Archeology; Literature.

Introdução

\footnotetext{
${ }^{1}$ Doutor em Filosofia pela Universidade Federal de São Carlos (UFSCAR), São Paulo Brasil. professor adjunto no Departamento de Filosofia da Universidade Estadual do Centro-Oeste (UNICENTRO), Paraná - Brasil. E-mail: augustobach@yahoo.com.br
} 
É em 1966, por intermédio da publicação de As Palavras e as Coisas, que a notoriedade pública alcança Foucault. Sucesso de venda e edição cuja importância quiçá não seja igual à soma de mal-entendidos que engendrará. Esta obra, simultaneamente filosófica e de história das ciências, difícil e de complexa argumentação, abraçando quatro séculos de pensamento ocidental, tem o objetivo (definido em seu subtítulo) de realizar uma arqueologia das ciências humanas. Na composição da obra que podemos chamar de "a arqueologia de nossa cultura", percebe-se dois grandes momentos. $\mathrm{O}$ primeiro, correspondente à primeira parte do livro, retraça o destino do pensamento ocidental do século XVI ao fim do século XVIII, enquanto o segundo, correspondente à segunda parte, evoca a reestruturação de tal pensamento desde o século XIX e conclui a respeito da situação, neste novo dispositivo teórico, das ciências humanas.

Mas, afinal, a que se deve esta periodização destacada por Foucault, se o empreendimento metodológico da arqueologia repetidamente afirmou não estar subordinado aos pressupostos de uma progressiva história dos saberes? Sabe-se que a história tradicional das ciências se apresenta habitualmente como o relato da conquista gradual, em um domínio do saber, de cientificidade repousando sobre o postulado da afirmação progressista e contínua de uma racionalidade científica. A história, conforme esta concepção organizar-se-ia a partir do paradigma da narrativa de acontecimentos cronológicos tomados em uma hierarquia de determinações. Ora, demonstrar o infundado desse gênero de pesquisa foi sempre uma característica da filosofia foucaultiana. Com esse propósito de fato, necessário se faz ao arqueólogo abandonar a velha concepção etnocêntrica de civilização como um estado de coisas ideal de que gozaria o Ocidente em seu estágio moderno e ao qual deveriam atingir todos os demais estágios primitivos de nossa cultura, sob a tutela das noções e conceitos mais avançados ou científicos. Seria mais transparente e neutro imaginarmos então uma sequencia aberta e infinita de transformações, pois sem começo nem fim, no desenrolar dos acontecimentos abrindo mão das ilusões míticas da origem primeira e de toda e qualquer interpretação triunfalista da história. Não mais um pensamento da história subordinado à lei do Um, muito menos a promessa de submissão a uma melhor dominação na serena crônica horizontal dos grandes acontecimentos, mas uma história que não coincide com a consciência que os homens dela tiveram; sempre diferente do que habitualmente se crê e irredutível a uma síntese subjetiva. Ipso facto, Foucault, em As Palavras e as Coisas, não tomará como ponto de referência a autoridade científica dos enunciados das ciências empíricas constituídas no século XIX para julgar retrospectivamente a pertinência dos enunciados clássicos do século XVII e XVIII; mas se contenta em comparar sistematicamente os saberes contemporâneos de uma dada episteme para encontrar aí seu princípio ordenador oculto. 
Pois aquele que opera uma leitura dos acontecimentos sem critérios de apoio à sua linguagem tem poucos elementos para fixar a origem e o término dos universos simbólicos. Esta orientação anti-totalizadora e asistemática das análises de Foucault, sua preferência por níveis de historicidade alheios ao cômputo continuista, evolutivo e atenuador do conflito, desmancha a associação romântica entre o heroísmo do sujeito e a realização de sua obra, signo do progresso de nossa civilização. Associação entre autor e obra, aliás, cujo potencial de redenção harmonizadora de nossa humanidade anima os esquemas intelectuais da fenomenologia. Há sempre uma nostalgia do Uno e da identidade por trás de nossas filosofias historicamente constituídas, uma vontade de verdade que se esconde atrás de seus humanismos e racionalismos dialéticos, da obsessão em reconduzir a origem e a gênese às formas transcendentais do sujeito. Já para um antifilósofo obstinado tal como se pretendia Foucault, a filosofia seria apenas um justificativa da ordem estabelecida que legitima o conhecimento empírico através de suas determinações transcendentais. Por sua própria conta e risco, Foucault deseja encarar a história sob outro prisma, enxergando cortes, descontinuidades entre as etapas descritas e imprimindo nela a fecundidade de seu novo pensamento.

A asserção foucaultiana em As Palavras e as Coisas de que em cada momento histórico dado existe somente uma e única episteme poderia nos fazer acreditar, primeiramente, que entre uma e outra episteme haveria uma dobra irredutível e intransponível; uma lacuna abismal representada pelas mutações epistemológicas doravante não explicadas ou pensadas por Foucault. Os espaços respectivos a cada episteme não poderiam bem comportar qualquer tipo de fissura em suas respectivas unidades. ${ }^{2}$ Todavia, acreditamos que seja possível encontrar no elemento literário de suas análises o fio condutor que permeia essas diferentes configurações do saber em meio a suas diversas ordenações espaciais. Será preciso que mantenhamos em suspenso a resposta a essas questões e, pacientemente, sigamos o primeiro nível da "disposição manifesta" do espaço dos saberes percorrida pela arqueologia.

Muito embora exista a possibilidade de identificarmos um percurso unificador dos saberes ao longo dos séculos na démarche foucaultiana, é preciso termos em mente que este "desenvolvimento" não se dá inicialmente de uma forma linear, contínua e progressista, tal qual supunham os estudos dos historiadores tradicionais das ideias; pois é a própria arqueologia, afinal,

\footnotetext{
2 Esta perspectiva é de fato muito bem sustentada pelo próprio Foucault de modo intermitente em alguns momentos de sua argumentação: "Trata-se de modos fundamentais do saber que suportam em sua unidade sem fissura a correlação segunda e derivada de ciências e de técnicas novas com objetos inéditos. A constituição desses modos fundamentais está sem dúvida enterrada longe, na espessura das camadas arqueológicas." (FOUCAULT, 1998; p.268 [265]).
} 
quem não cessa de assinalar sulcos e cortes na superfície histórica dos saberes.

\begin{abstract}
Pode-se perfeitamente escrever uma história do pensamento na época clássica, tomando (...) debates como pontos de partida ou como temas. Mas não se fará então mais que a história das opiniões, isto é, das escolhas operadas segundo os indivíduos, os meios, os grupos sociais; e é todo um método de inquirição que está implicado. Se se quiser empreender uma análise arqueológica do próprio saber, então não são esses debates célebres que devem servir de fio condutor e articular o propósito. É preciso reconstituir o sistema geral de pensamento, cuja rede, em sua positividade, torna possível um jogo de opiniões simultâneas e aparentemente contraditórias. É essa rede que define as condições de possibilidade de um debate ou de um problema, é ela a portadora da historicidade do saber. [...] E desse percurso, percebe-se o sulco na superfície histórica dos temas, dos debates, dos problemas e das preferências de opinião. Os conhecimentos atravessaram de ponta a ponta um 'espaço de saber' que havia sido disposto de uma só vez, no século XVII, e que só devia ser encerrado 150 anos mais tarde. (1998; p.90 [89]).
\end{abstract}

Embora, como visto acima, Foucault rejeite a ideia tradicional dos historiadores de progresso no pensamento e no saber e construa em seu lugar uma história do saber assinalada por nítidas descontinuidades, veremos que, associado paradoxalmente ao seu caráter crítico e antiprogressista dos demais saberes, está presente em sua démarche filosófica um uso singular das artes da literatura e da pintura que esconde uma finalidade em sua argumentação. Escrever, para Foucault, obedece necessariamente a uma específica estratégia. Obras literárias como Dom Quixote de Cervantes, Justine e Juliette do Marquês de Sade e a pintura Las Meninas de Velásquez são utilizadas pela arqueologia como alegorias que tomam por objeto de estudo a episteme na qual se encontram em uma posição de borda exterior, limite. ${ }^{3}$ Diferentemente dos outros discursos analisados, elas se encontram presentes em As Palavras e as Coisas numa outra dimensão, mais profunda. É necessário dizer também que, ao emprestar a determinadas obras o papel alegorizador das profundas acomodações epistêmicas, Foucault inevitavelmente estará incorrendo em um prejuízo antropológico do qual obstinadamente tanto desejara se afastar. Será partindo desta "desconfiança alegórica" de Foucault, de sua utilização inusitada da arte e da literatura versando sobre uma dada configuração

\footnotetext{
${ }^{3}$ Nossas análises, embora anunciem uma sutil diferença no que diz respeito à associação entre literatura e arqueologia, foram primeiramente inspiradas nos comentários de John Rajchman. "Parece ser esse, de fato, o elo geral entre as duas histórias de Foucault, a história do saber e a história da literatura e da pintura. As artes são alegorias metaepistêmicas dos profundos arranjos que tornam possível o saber. [...] sua história literária contém uma teleologia oculta." (RAJCHMAN, J; 1992, p. 26).
} 
epistemológica como um todo, articulando e relacionando a descontinuidade assinalada entre dois campos de saberes distintos, que poderemos entrever no percurso arqueológico uma história um jogo de antecipações e sucessões; o fio condutor de um mesmo movimento amparador da descrição de cada episteme e que se destina a diagnosticar a "situação da linguagem em nossos dias".

Este artigo, por sua vez, procurará mostrar como Michel Foucault operou a leitura dos saberes da civilização ocidental em sua grande obra As Palavras e as Coisas. Ao longo dos anos sessenta, Foucault sempre esteve preocupado acerca da maneira com que usualmente nos concebemos. Ao investigar a linguagem racional ele descobriu uma surpreendente modulação discursiva que esconde nossas mais básicas escolhas. Ele a chamou de literatura. Cavando até o mais profundo e desconhecido nível de nossa cultura, a arqueologia de Foucault compartilha desde a publicação de História da Loucura em 1961 algumas noções filosóficas que, acima de tudo, demandam um esclarecimento prévio antes de qualquer interpretação de seu pensamento.

\section{A Episteme do renascimento e a idade clássica da representação}

O primeiro dos sistemas de pensamento analisado por Foucault, abrangendo a Idade Média e predominante até o século XVI, é o chamado Renascimento. O problema da ordem intrínseca e anterior aos saberes, nesta episteme, é marcado a partir da noção mais vaga e abrangente da semelhança. No entrelaçamento das palavras e as coisas, todos os saberes, seja no espaço ou no tempo, relacionam-se por semelhança; como se entre estas duas não houvesse a mínima descontinuidade. Uma forte identidade entre a linguagem e o real, centrada nesta ideia de semelhança, permite que a interpretação da palavra escrita depositada no mundo equivalha ao conhecimento do real e da verdade sobre as coisas. A semelhança, aqui, cumpre um papel fundamental na ordenação do saber ao assegurar uma passagem contínua das palavras às coisas; pois nas formas da linguagem renascentistas refletem-se as formas substanciais dos seres. O conhecimento do mundo é operado mediante a interpretação das palavras.

No seu ser bruto e histórico do século XVI, a linguagem não é um sistema arbitrário; está depositada no mundo e dele faz parte porque, ao mesmo tempo, as próprias coisas escondem e manifestam seu enigma como uma linguagem e porque as palavras se propõem aos homens como coisas a decifrar. A grande metáfora do livro que se abre, que se soletra e que se lê para conhecer a natureza não é mais que o reverso visível de uma outra transferência, muito mais profunda, que constrange a linguagem a residir do lado do mundo, em meio às plantas, às ervas, às pedras e aos animais. (FOUCAULT, 1998; p.51 [4950]) 
Assim o mundo, a "prosa do mundo", é como uma escrita que apela para além dela um comentário, e aquém da interpretação das palavras está o texto escondido onde é preciso encontrar o sentido. Digamos, portanto, que a interdependência entre a palavra depositada no mundo e o conhecimento das coisas da natureza é tamanha que nada pode subsistir aí como um resíduo fora da linguagem. No Renascimento, a palavra é uma coisa; não havendo mais que um só ser, uma linguagem real, misteriosa, opaca e misturada às figuras do mundo.

Tal estranho universo simbólico em que as palavras possuem o poder de espelhar plenamente o mundo certamente desaparecerá de nosso campo epistemológico. O Renascimento nos remete a uma forma de inocência ou de um narcisismo perdido do signo, do qual estaríamos agora na maior das distâncias. Desta "idade de ouro do signo"4, não obstante, quiçá possamos reencontrar qualquer traço em nossos dias no que chamamos hoje de literatura e seu universo poético que, segundo Foucault, inventamos neste último século para compensar o "funcionamento significativo da linguagem". Eis aqui o início de um vínculo intermitente que a arqueologia manterá com a análise literária no decorrer de $A s$ Palavras $e$ as Coisas. ${ }^{5}$ Pois se o mundo deixou de ser uma linguagem, Foucault reencontrará no século XIX o "ser vivo da linguagem" manifestado em sua densidade pela literatura moderna, ainda que esteja ausente uma solução de continuidade histórica entre essas duas concepções, ao inexistir

\footnotetext{
${ }^{4}$ A expressão é retirada de François Wahl em Estruturalismo e Filosofia. Num artigo consagrado ao estudo de As Palavras e as Coisas, o filósofo francês Wahl diagnostica, para além do trabalho de descrição das epistemes, uma paixão foucaultiana "não tematizada, um parti pris do pleno, que dá curiosamente à história trilhada por les Mots et les Choses o andamento de uma decadência, de um afastamento cada vez maior do que toma então a figura da idade de ouro do signo" (WAHL, FRANÇOIS; 1990, p.10). Esta constatação permitirá a Wahl enxergar na démarche foucaultiana um projeto fenomenológico que procura o ser vivo da linguagem no que chamamos modernamente de literatura. A literatura, tendo para Foucault a "função de intuição doadora desse objeto original que é a linguagem", compensaria em nossos dias o uso instrumental e transitivo da linguagem em sua função significativa.

${ }^{5}$ Conforme Machado: "É nesse momento de sua trajetória que a análise da literatura se vincula mais fortemente à análise arqueológica, como se o livro que pode ser considerado a conclusão do estudo sobre as ciências do homem na modernidade funcionasse ao mesmo tempo como unificação dos estudos sobre a linguagem literária, que aqui receberia uma teoria geral que desse conta de sua função em relação a esses outros saberes de nossa época, apresentando-lhes suas margens: os limites da loucura, da morte, do impensável..." (MACHADO, R; 2000 p.107). Será preciso justamente constatarmos que essa "teoria geral" que unifica, consoante Machado, os estudos sobre a literatura está justificada por uma teoria da história, desdobrada em três níveis, presente no Prefácio de As Palavras e as Coisas, ainda que de modo quase inconfesso. A posição marginal, limítrofe da literatura perante os demais saberes servir-nos-á como um instrumento de explicação das passagens entre as configurações de saberes.
} 
agora o texto fundamental que fazia do mundo um livro de signos espessos no universo simbólico do Renascimento.

\begin{abstract}
Nada mais há em nosso saber nem em nossa reflexão que nos traga hoje a lembrança desse ser. Nada mais, salvo talvez a literatura. (...) Na idade moderna, a literatura é o que compensa (e não o que confirma) o funcionamento significativo da linguagem. Através dela o ser da linguagem brilha de novo nos limites da cultura ocidental - e em seu coração - pois ele é, desde o século XVI, aquilo que lhe é mais estranho; porém, desde esse mesmo século XVI, ele está no centro do que ela recobriu. Eis por que, cada vez mais, a literatura aparece como o que deve ser pensado; mas também, e pela mesma razão, como o que não poderá em nenhum caso ser pensado a partir de uma teoria da significação. (...) A partir do século XIX, a literatura repõe à luz a linguagem em seu ser: não, porém, tal como ela aparecia ainda no final do Renascimento. Porque agora não há mais aquela palavra primeira, absolutamente inicial, pela qual se achava fundado e limitado o movimento infinito do discurso; doravante a linguagem vai crescer sem começo, sem termo e sem promessa. É o percurso desse espaço vão e fundamental que traça, dia a dia, o texto da literatura. (FOUCAULT, 1998; p.59-60 [58-59]).
\end{abstract}

Paulatinamente, com a chegada da idade clássica, esse entrecruzamento entre as palavras e as coisas no mundo do século XVI vai se deteriorando à medida que a linguagem se destaca do mundo em que vivia para se refletir em pura discursividade representativa. Nessa nova episteme, o discurso já não estabelece uma semelhança com a realidade, remetendo a uma raiz comum entre ambos, mas erige-se como uma representação das coisas, um modo de ordená-las e de conhecê-las mediante a análise. Durante toda a idade clássica, a linguagem fora posta e refletida como discurso, ou seja, como uma análise espontânea da representação. Com a desagregação da episteme fundada na semelhança, uma descontinuidade que separa agora a linguagem do real torna-se manifesta. A relação que a própria linguagem mantém com o real será avaliada agora de acordo com a ordem que fundamenta a gestação da nova episteme; qual seja, a capacidade das palavras de se ajustarem ao conteúdo das representações. Entre o signo e a coisa, abre-se uma lacuna; o mundo, agora duplicado por um sistema de signos que dele se distingue, perde seu caráter opaco e misterioso para abrir-se à possibilidade do iluminado conhecimento representativo. A ordem doravante não estará mais no movimento incessante das semelhanças, o pensamento não será mais dirigido por uma visão de mundo cosmológica na qual as coisas estão concatenadas segundo relações de analogia, mas no estabelecimento de identidades e de diferenças onde se sucedem ou se justapõem as representações. 
A profunda interdependência da linguagem e do mundo se acha desfeita. O primado da escrita está suspenso. Desaparece então essa camada uniforme onde se entrecruzavam indefinidamente o visto e o lido, o visível e o enunciável. As coisas e as palavras vão separar-se. (...) O discurso terá realmente por tarefa dizer o que é, mas não será nada mais do que o que ele diz. Imensa reorganização da cultura de que a idade clássica foi a primeira etapa, a mais importante talvez, posto ser ela a responsável pela nova disposição na qual estamos ainda presos - posto ser ela que nos separa de uma cultura onde a significação dos signos não existia, por ser absorvida na soberania do Semelhante; mas onde seu ser enigmático, monótono, obstinado, primitivo, cintilava numa dispersão infinita. (FOUCAULT, 1998; p.59 [58]).

Enquanto na Renascença a linguagem se dava em seu ser bruto, com os signos depositados no mundo, a linguagem possuía um estatuto privilegiado. No mundo todo, podia-se ler uma fala inscrita e depositada na ordem das coisas; uma fala, todavia, anterior a toda representação. A inversão ocorrida no modo de perceber a linguagem, na passagem do século XVI para o século XVII, consistiu, pois, no fato do signo deixar de ser uma assinatura misteriosa do mundo para vir a ser transparente à ideia e localizar-se no interior mesmo do conhecimento manifesto. A partir dessa comparação, vê-se que a linguagem é, na Idade Clássica, o pressuposto do conhecimento organizado. Embora sua continuidade com o real assegurada pela ordem da semelhança tenha sido interrompida ao se elidir em sua natureza de discurso representativo, é a linguagem quem continua a providenciar aos signos todas as suas representações, ao subsistir ainda na representação o seu funcionamento e suas virtudes de discurso. O papel do saber agora será o de fabricar uma língua bem feita que superestruture o real, uma linguagem artificial, uma ordem simbólica e convencional dos signos. Alojando-se inteiramente na representação, a linguagem deixa de ser a fala das coisas, depositária de um sentido inesgotável, para se tornar a pura discursividade de um pensamento capaz de representar o mundo; ela perde, enfim, seu estatuto de texto do mundo para apagar-se na forma de um discurso que reduplica simbolicamente a realidade. O que importa então conhecer do discurso não é mais o que eventualmente estaria silenciado ou escondido de um modo até então impensado, mas o seu funcionamento representativo ao invés de sua exegese. O conhecimento doravante não será mais a "prosa do mundo" na medida em que o saber clássico fizer a linguagem desaparecer sob a forma de representação.

Doravante, o Texto primeiro se apaga e, com ele, todo o fundo inesgotável de palavras cujo ser mudo estava inscrito nas coisas; só permanece a representação, desenrolando-se nos signos verbais que a manifestam e tornando-se assim discurso. $\mathrm{O}$ enigma de uma palavra que uma segunda linguagem deve interpretar foi substituído pela discursividade essencial da 


\begin{abstract}
representação. (...) Ora, quando esse discurso se torna, por sua vez, objeto de linguagem, não é interrogado como se dissesse alguma coisa sem o dizer, como se fosse uma linguagem retida em si mesma e uma palavra fechada; não se busca mais desvelar o grande propósito enigmático que está oculto sob seus signos; pergunta-se-lhes como ele funciona: que representações ele designa (...) que jogo de substituições lhe permite assegurar seu papel de representação. (...) Uma vez elidida a existência da linguagem, subsiste na representação apenas seu funcionamento: sua natureza e suas virtudes de discurso. (FOUCAULT, 1998; p.94-97 [93-96]).
\end{abstract}

$\mathrm{O}$ discurso, que aparece quando a linguagem desaparece e desaparece quando a linguagem aparece, é a imagem pálida, um "fantasma" da linguagem que existia na época renascentista. Aqui, o termo discurso é empregado por Foucault em um sentido específico. Qualidades como intransitividade e auto-referência, que caracterizarão a literatura da idade moderna consoante Foucault, estão dele ausentes. Sua única função é de servir como uma representação transparente das coisas permanecendo no exterior delas. Vemos, portanto, que a existência concomitante da linguagem e do discurso em uma mesma episteme é antitética e até impossível. No início do século XVII, quando a linguagem presente no século XVI desaparece, tudo o que restará dela é sua função de representação, sua natureza, seu funcionamento e suas virtudes de discurso. Inversamente, quando a existência da linguagem, pois, iniciar o seu processo de retorno - e Foucault afirma que ele começa no final do século XVIII por meio do funcionamento significativo da linguagem e do aparecimento da literatura moderna, embora não se manifeste ainda em sua unidade e soberania - então o discurso desaparecerá.

Esta tese foucaultiana sobre a síncope, o desaparecimento, e o retorno manifesto do protagonista principal de As Palavras e as Coisas, a linguagem, está intimamente associada com uma consideração sobre o estatuto dos signos e da significação. Deve-se o fenômeno do recuo da linguagem, diagnosticado no início do século XVII, a uma mudança fundamental na estrutura do signo. Dos estóicos ao Renascimento, o sistema dos signos na cultura ocidental era ternário. No sistema do século XVI, significante e significado estavam vinculados entre si por uma relação de semelhança. Mas no início do século XVII, o sistema dos signos tornou-se binário mediante uma relação arbitrária estabelecida entre o significante e o significado. A relação do significante com o significado é o vínculo estabelecido entre a ideia de uma coisa e a ideia de uma outra. A determinação do elemento significante, seu conteúdo, é aquilo que ele representa; e a propriedade fundamental do signo na época clássica é a representação. Mas para que este elemento significante se torne signo, é preciso que essa representação se encontre, ao mesmo tempo, representada 
nele. Foi esta mudança, Foucault sustenta, que assinalou o desaparecimento da linguagem e sua substituição por uma suposta transparência discursiva.

Teoria dual do signo, que se opõe sem equívoco à organização mais complexa do Renascimento; então a teoria do signo implicava três elementos perfeitamente distintos: o que era marcado, o que era marcante e o que permitia ver nisto a marca daquilo; ora, este último elemento era a semelhança - o signo marcava na medida em que era 'quase a mesma coisa' que o que ele designava. É esse sistema unitário e triplo que desaparece ao mesmo tempo que o 'pensamento por semelhança', e que é substituído por uma organização estritamente binária. Mas há uma condição para que o signo seja realmente essa pura dualidade. Em seu ser simples de ideia ou de imagem ou de percepção, associada ou substituída a uma outra, o elemento significante não é signo. Ele só se torna signo sob a condição de manifestar, além do mais, a relação que o liga àquilo que o significa. É preciso que ele represente, mas que essa representação, por sua vez, se ache representada nele. (FOUCAULT, 1998; p.79 [78]).

E é com o intuito de ressaltar ainda a importância dessa transparência discursiva, origem de todo conhecimento clássico, e realizar uma história dos saberes somente a partir daquilo que lhes é contemporâneo, que Foucault afirma ser impossível uma teoria da significação na época clássica. Contra uma perspectiva anacrônica de leitura das epistemai anteriores, seria preciso não emitir juízos sobre o passado mediante critérios fornecidos pelos saberes do presente:

... essa extensão universal do signo no campo da representação exclui até a possibilidade de uma teoria da significação. Com efeito, interrogar-se sobre o que é a significação supõe que esta seja uma figura determinada na consciência. Mas, se os fenômenos nunca são dados senão numa representação que, em si mesma e por sua representatividade própria, é inteiramente signo, a significação não pode constituir problema. Mais ainda, ela nem sequer aparece. Todas as representações são ligadas entre si como signos; e todavia, nenhuma atividade específica da consciência pode jamais constituir uma significação. [...] Não há sentido exterior ou anterior ao signo; nenhuma presença implícita de um discurso prévio que seria necessário restituir para trazer à luz o sentido autóctone das coisas. Mas também não há ato constituinte da significação nem gênese interior à consciência. É que entre o signo e seu conteúdo não há qualquer elemento intermediário e nenhuma opacidade. (FOUCAULT, 1998; p.81 [79-80]).

O fato do significado se alojar sem resíduo ou sem opacidade alguma no interior iluminado da representação, aonde se dão os fenômenos, faz com que o estatuto da significação permaneça simplesmente impensado para a 
época clássica. Dito de maneira sintética, não havia ainda (tal como irá haver em nossos dias) consciência epistemológica da significação enquanto tal. A representação, por seu jogo de representatividade própria, faz com que a significação não possa constituir-se como um problema a ser pensado e tematizado pelos saberes clássicos. Ou seja, ela (a significação) não apenas não aparece, como também permanece ainda presente no espaço da episteme clássica de um modo até então oculto, latente ou suprimido.

Pois bem, é fato que aqui nos deparamos com uma melindrosa questão sobre a qual necessitamos de abrir um pequeno parêntese. Pois a sutileza da argumentação arqueológica sobre a diferença de estatuto da significação na era da representação e na época moderna é objeto ainda de alguns mal-entendidos na literatura foucaultiana. ${ }^{6}$ É preciso, pois, constatar que não seria tarefa do arqueólogo explicar a distinção entre os conceitos de "representação" e "significação" se Foucault limita-se a um exercício descritivo de mapeamento dos saberes. E mais, não se pode declarar que Foucault "fracasse em explicar claramente a diferença" entre estes dois conceitos quando, simplesmente, o autor não notou entre eles qualquer dessemelhança.

Para Foucault, a época clássica identifica ambos em seu sucesso de representação do real, pois é justamente ela a responsável por nos separar da cultura renascentista onde a significação dos signos não existia. E apenas na idade moderna a significação tornar-se-á um problema a ser pensado e mapeado, portanto, pela cartografia foucaultiana, devido justamente à perda de transparência da representação no processo de justificação integral do real. Foucault não está dizendo, pois, que simplesmente não existia o conceito de "significação" ${ }^{7}$ antes do século XIX; mas que a significação

\footnotetext{
${ }^{6}$ Vide o exemplo de Allan Megill: "Infelizmente, deixando inteiramente de lado a questão da exatidão histórica daquilo que Foucault argumenta, sua análise dos signos e da significação permanece obscura, mesmo depois de ter-se feito o considerável esforço de ler sua algo idiossincrática terminologia e o apanhado do conjunto do livro. O ponto em questão será encontrado em seu fracasso em explicar a distinção entre a representação e a significação. Representação, ele argumenta, é a característica da clássica episteme do século XVII e XVIII; enquanto a significação é a característica da moderna episteme que começa no século XVIII e que está agora, ele sugere, na ocasião de sua morte. E mais, ele não nos diz qual, afinal, a distinção entre a representação e significação. Nem faz ele suficientemente clara as implicações para a distinção do conceito de signo, que permanece binário em sua estrutura através das epistemes clássica e modernas. A tendência da análise de Foucault sugere que ele veja os dois conceitos como variantes um do outro, pois ambos existem sob a égide de uma estrutura binária do signo e numa economia em que a 'linguagem' sequer existe (representação) ou existe apenas num aspecto fragmentário (significação).” (MEGILL, A; 1996 p.209).

${ }^{7}$ Dreyfus e Rabinow foram mais esclarecedores a respeito da diferença que marca o classicismo e o século XIX. "Na Época Clássica, o homem não era $o$ produtor, $o$ artíficeDeus; mas enquanto foco de esclarecimento, ele era um dos artífices. Havia um mundo em si criado por Deus. O papel do homem era esclarecer a ordem do mundo. Ele o fez, conforme vimos, através de ideia claras e distintas. A ideia central era que o suporte da representação fosse seguro e transparente. A função do pensador era fazer uma descrição
} 
como um conceito fundamental, não derivado ou superficial, não veio ainda a se constituir como um problema para os séculos XVII e XVIII. Ela só aparecerá como uma questão e como objeto de estudo para os saberes quando a capacidade do discurso clássico em representar a totalidade do real, devido a um segundo acontecimento arqueológico de nossa cultura, for abalada em fins do século XVIII. Não se pode, portanto, criticar Foucault por ter se confundido ao não explicar corretamente a "distinção" entre significação e representação.

O que pode ser questionado, entretanto, são os pressupostos de seus cortes epistemológicos, de seus julgamentos que assinalam um conceito como pertencente a um determinado contexto epistêmico ocupando uma posição superficial e, em outro, ocupando uma profunda e fundamental localização. Seu método arqueológico deixa-nos entrever que as distinções entre as configurações de saber sejam praticamente "sem comércio", "sem recurso", e que o arqueólogo seja o único a estar em posição de nos dizer qual conceito pertence, pois, a qual episteme. Pode-se perceber, no entanto, que Foucault começa a utilizar aqui manifestamente a expressão consciência, tão cara ao seu método, para descrever a oposição que marcará a descontinuidade entre as epistemaï clássica e moderna. A eclosão da significação como um problema manifesto a ser pensado pelos saberes, constituída por uma atividade específica da consciência no século XIX, ocorrerá a partir do nível mais fundamental de nosso solo; e a consciência epistemológica da significação ausente numa dada episteme estará presente em outra. Tais pressupostos, subjacentes aos juízos formulados por Foucault, deverão ser precisamente investigados em momento mais oportuno. Voltemos aos primeiros séculos trabalhados pela arqueologia.

\section{Entre o Classicismo e o Renascimento (Dom Quixote de Cervantes)}

Desta passagem do estatuto da linguagem renascentista, vinculada embrionariamente ao mundo, ao seu desaparecimento na Idade Clássica quando então se tornou discurso representativo do real, Foucault, já o dissemos, não fornece grandes justificativas. A abertura de um novo espaço dos saberes, onde, por uma quebra essencial na cultura do mundo ocidental, a questão não será mais a da similitude entre as coisas, mas sim a da identidade e das diferenças entre as representações, permanecerá impensada e inexplicada pela arqueologia enquanto esta for compreendida

artificial, uma ordem convencional dos signos. Mas não foi o homem quem lhes deu sentido. É isso que Foucault quer dizer quando afirma que não havia uma teoria da significação na Época Clássica. O homem esclarecia, mas não criava; ele não era fonte transcendental de significação. Deste modo, se tivéssemos que perguntar qual a atividade própria do sujeito - o 'eu penso' - nós teríamos a resposta relativamente simples de que é a tendência a alcançar a clareza dos conceitos.” (DREYFUS Y RABINOW; (1998) P.22). 
desassociadamente do papel exercido pela literatura. ${ }^{8}$ Embora Foucault apenas episodicamente dirija sua palavra à dimensão fundamental dos saberes que descreve, explicitamente não procure realizar o contorno dos sistemas descritos, ou fazer o pensamento assenhorar-se "de si mesmo na raiz de sua história" e "interrogá-lo na direção por onde ele escapa a si mesmo", limitando-se dessa maneira a acolher a descontinuidade assinalada entre as palavras e as coisas na ordem empírica e em sua disposição manifesta; nem por isso devemos dizer que as mutações arqueológicas permaneçam como um aspecto demasiado sombrio de seu pensamento. Muito embora a lei desse deslocamento epistêmico atue sem que a possibilidade estrutural do acontecimento histórico e de seu lugar possa ser analisados por si mesmos, e ainda que a pena do arqueólogo permaneça retida pela impossibilidade de um esgotamento integral do solo epistemológico que o conduziria, deste modo, à disposição fundamental dos saberes e a uma explicação satisfatória - e quiçá universal - sobre as

\footnotetext{
${ }^{8} \mathrm{Na}$ tentativa de fornecer um critério explicativo para as mudanças nos espaços de saberes, François Wahl encontrará no conceito de signo, definindo-o a partir de Barthes e Agostinho como o estabelecimento de "uma relatio entre dois relata", o elemento que governa as mutações epistêmicas. "Que haja, oculta ('impensada') no coração de cada estado de cultura, 'uma modalidade da ordem', que se dá como 'o solo positivo' sobre cujo fundo vão necessariamente elaborar-se a classificação e a interpretação das experiências; que essa ordem intervenha de cada vez como uma condição de 'possibilidade' para as formas hierarquizadas do conhecimento e de sua teorização; que ela funcione, em suma, como um 'a priori histórico': tais são os elementos que ministra Michel Foucault para uma primeira definição de epistemê. Eles deixam curiosamente à sombra um conceito que vai se revelar, ao longo de toda a sondagem histórica empreendida por les Mots et les Choses, capaz de reger, por sua vez, a ordem em suas mutações: o conceito de signo [...] tudo isso que faz a epistemê não pode evidentemente caminhar sem que seja inscrita para nós em cada coisa, de um modo ou de outro, a configuração de suas relações: de sorte que pensar uma leve a pensar as outras" (WAHL, 1990; p.16). Cada configuração de saber implica, segundo Wahl, toda uma série de interrelações. Cada figura dentro do quadro da configuração funciona como representativa de outros elementos e ao mesmo tempo como representativa da configuração em geral. Da mútua relação entre a episteme e a configuração de suas relações, ele afirma: "A epistemê, como toda ordem, envolve uma semiologia". Dentro de cada episteme, portanto, as relações, e deste modo os signos, são de um mesmo tipo. Tão longe as relações entre as relata retenham a mesma natureza, a episteme permanece a mesma. Mas quando a natureza da relação entre as relata se modifica, então a episteme muda. "Os edifícios de saber abalam-se, porém, e há mudança de epistemê, quando é a relatio que muda, quando varia a relação atribuída ao signo em face do que ele significa: quando isso não significa mais a mesma coisa que significar." (WAHL, 1990; p.19). Muito embora a singular leitura de Wahl revele uma extrema acuidade filosófica, não poderemos sustentar aqui sua tese de que a episteme envolva uma semiologia. Esta proposta para detecção da mudança epistêmica não será de bom uso quando estivermos trabalhando a segunda mutação que separa o classicismo da modernidade. Pois o estatuto do signo, que permanecerá binário em ambas as configurações de saber, implica a interpretação dos séculos XIX e XX como um mero "retoque epistemológico", apenas uma "reorganização de setores no interior de uma classificação intocada em seu conjunto" e não como uma mudança global de ordenação dos saberes.
} 
mudanças epistêmicas; é preciso constatar que o percurso da arqueologia ainda assim não carece de um esteio que o permita e o autorize a continuar suas investigações.

Podemos, pois, encontrar no uso alegórico de obras literárias, numa "desconfiança alegórica" não tematizada de Foucault, uma "explicação" que contorne e aglutine essa enigmática descontinuidade entre as epistémaï. Se as obras de arte são "alegorias meta-epistêmicas dos profundos arranjos que tornam possível o saber", como quer Jonh Rachman, é a literatura e a história literária daí subsequente que servem de apoio à linguagem da história arqueológica que se quer sem metalinguagem. Dom Quixote de Cervantes é aqui o caso exemplar da mudança que nos concerne.

Com suas voltas e reviravoltas, as aventuras de Dom Quixote traçam o limite: nelas terminam os jogos antigos da semelhança e dos signos; nelas já se travam novas relações. Dom Quixote não é o homem da extravagância, mas antes o peregrino meticuloso que se detêm diante de todas as marcas da similitude Ele é o herói do Mesmo. (...) Dom Quixote desenha o negativo do mundo do Renascimento; a escrita cessou de ser a prosa do mundo; as semelhanças e os signos romperam sua antiga aliança; as similitudes decepcionam, conduzem à visão e ao delírio; as coisas permanecem obstinadamente na sua identidade irônica; não são mais do que são; as palavras erram ao acaso, sem conteúdo, sem semelhança para preenchê-las; não marcam mais as coisas; (...) A verdade de Dom Quixote não está na relação das palavras com o mundo, mas nessa tênue e constante relação que as marcas verbais tecem de si para si mesmas. A ficção frustrada das epopéias tornou-se no poder representativo da linguagem. As palavras acabam de se fechar na sua natureza de signos". (FOUCAULT, 1998; p.61 [60])

Primeiramente, na originalidade de sua análise, vemos Foucault voltar-se contra as interpretações mais difundidas do livro de Cervantes. Ao contrário do senso comum estabelecido por parte da crítica literária, que terminou por salvaguardar a figura de Dom Quixote como um personagem ridículo e extravagante - daí quiçá a etimologia da expressão quixotesca, Foucault destaca a relação do herói "cervantiano" com as palavras e as coisas para encontrar aí uma relação de sucessividade ${ }^{9}$ entre as epistémaï renascentistas e clássicas. É o caráter de limite e de borda exterior traçado pelas aventuras do personagem, pois, que interessa a Foucault. Dom Quixote marca, ao mesmo tempo, o fim de uma era, a da semelhança, e o início de uma nova: a da representação. Tratando-se sempre de uma

\footnotetext{
9 Sucessividade ou progressividade, sejamos bem entendidos, que não deve ser aqui compreendida como um passo de adiantamento cultural da humanidade; idéia sempre tão combatida por Foucault. Mas tão somente como a sucessão entre os dois sistemas de pensamento articulados por meio da obra literária.
} 
semelhança frustrada, errando ao acaso e desprovida de conteúdo, que o herói encontra em sua tragédia, desclassifica-se ironicamente a ordem do saber em que se fundamentava a episteme renascentista. Há de se constatar, pois, que este aspecto desdenhador da ordem dos signos e similitudes renascentistas só é possível mediante a inauguração de uma nova ordem em que as palavras não habitam mais o mundo como marcas das coisas, mas se fecham em sua natureza de signo assumindo sua função de discurso representativo do real. Dom Quixote possui, portanto, uma positividade que, embora pertencente à episteme clássica - a verdade de Dom Quixote está na relação que as representações tecem entre si, diz-nos Foucault - articula e reúne a contraposição de duas ordens do saber fundamentadas em diferentes noções: a semelhança e a representação. Segundo as palavras do epistemólogo Georges Canguilhem, num artigo escrito no calor da publicação de As Palavras e as Coisas, Cervantes juntamente com Descartes encontrar-se-iam investidos, na obra de Foucault, de um poder judicatório ou crítico.

Descartes é um dos artesãos da partilha da norma que tem por efeito conjurar a loucura no espaço asilar onde a psicopatologia do século XIX a encontrou como objeto de saber. Cervantes é um dos artesãos do desvio que arrancou as palavras à prosa do mundo e as tornou capazes de ligarem-se umas às outras na cadeia dos signos e na trama da representação (CANGUILHEM, 1967, p. 599-600). ${ }^{10}$

Se um escritor ou autor, juntamente com outros, é capaz de ativamente influenciar, e ser assim responsabilizado pela mudança no estatuto dos signos, a passagem de uma época para a outra é uma questão cuja resposta nos introduz em mais uma melindrosa polêmica suscitada pela obra. Neste artigo, entre outras considerações, Canguilhem observa que As Palavras $e$ as Coisas fora escrita em um momento em que a Europa vivia um certo "espanholismo" que teria influenciado certas escolhas de Foucault. Certamente não é tarefa fácil avaliar com precisão a presença de Borges, Velásquez e Cervantes em uma mesma obra; contudo, julgamos que o termo "espanholismo", se representativo do espírito europeu da época em que o livro fora redigido, não esgota suficientemente o uso foucaultiano da obra de tais autores. Julgar uma obra apenas em termos de influência recíproca, e que por sua vez acaba por conferir à noção de autor atribuições mais que desejadas na condução das trocas epistemológicas, certamente nos afastaria

\footnotetext{
10 "Les Mots et les choses tem seu lugar de nascimento num texto de Borges, tendo recorrido a Velásquez e a Cervantès para lhes emprestar as chaves de leitura das filosofias clássicas, o ano exato onde a circular de convocação ao quarto Congresso mundial de psiquiatria em Madrid era ornamentada da efígie de Dom Quixote, o ano mesmo onde a exposição de Picasso em Paris nos recordou o enigma sempre atual da mensagem confiada ao quadro Les Ménines. Emprestemos então de Henri Brulard o termo de espanholismo para caracterizar o espírito filosófico de Foucault"(CANGUILHEM, G; 1967, p. 599-600).
} 
do espírito e da letra da própria arqueologia aqui perseguidos. É preciso lembrar, antes de mais nada, que o próprio método arqueológico de Foucault era avesso a tais alinhamentos e filiações:

[...] que uma reflexão sobre o histórico de um saber não pode mais contentar-se em seguir, através da sequiência dos tempos, o alinhamento dos conhecimentos; estes, com efeito, não são fenômenos da hereditariedade e de tradição; e não se diz o que os tornou possíveis enunciando o que era conhecido antes deles e o que eles, como se diz, 'trouxeram de novo'. A história do saber só pode ser feita a partir do que lhe foi contemporâneo e não certamente em temos de influência recíproca, mas em termos de condições e de a priori constituídos no tempo (FOUCAULT, 1998; p.223 [221])

Incidindo ainda exatamente sobre esta questão, conforme o comentador Ian Hacking ${ }^{11}$, devido a uma romântica concepção presente nas análises de História da Loucura, que enxergava o exercício do poder como repressão, a noção de autor permanece com sua devida relevância no que tange às considerações foucaultianas desse livro. Contudo, o privilégio concedido por Foucault ao regime discursivo, e a ausência de associações do discurso com o âmbito extra-discursivo em As Palavras e as Coisas, nos impediriam de estender o mesmo raciocínio a esta segunda obra. De acordo ainda com Hacking, a noção antropológica de autor, sujeito fundante e criador que se disfarça por detrás da obra, perderia sua relevância já nesta etapa da arqueologia. Ao sustentar que um conjunto de saberes, que podem ser enunciados em uma época específica, tem sua condição de possibilidade determinada não pela consciência soberana dos sujeitos, mas pela episteme que lhe serve de solo, Foucault torna irrelevante para suas análises das condições de possibilidade dos saberes a própria noção de autor. Em outras palavras, torna-se nítido em As Palavras e as Coisas a limitação do voluntarismo artístico de um autor na manipulação de uma comunidade de sentido, ou visão de mundo (Weltanschauung), e no processo de trocas ou passagens epistemológicas. A ênfase anteriormente atribuída à função do autor, o monarca da obra, é substituída agora pela noção de soberania epistêmica que rege as condições de possibilidade dos saberes.

\footnotetext{
11 "A despeito de tudo, A História da Loucura obedece à romântica convenção que enxerga o exercício do poder como repressão [...] O dramático e fundamental aspecto do recente trabalho de Foucault é a rejeição dessa idéia. Mas isto não ocorrerá somente em seus escritos sobre o poder, pois é já em suas reflexões sobre os saberes que esta conversão acontece. [...] Ele sustenta que uma classe de sentenças que podem ser enunciadas num específico tempo e espaço não é determinada pelo desejo consciente dos falantes. A possibilidade do verdadeiro ou do falso não reside num desejo pessoal de comunicar-se. Deste modo, o autor mesmo torna-se irrelevante para a análise de tais 'condições de possibilidade'. [...] Tais condições irão jazer no 'profundo' conhecimento do tempo." (HACKING, Ian; A arqueologia de Foucault (1994) p.30 -32).
} 
Vê-se, contudo, que embora Foucault tenha descartado a noção subjetiva de autor de suas análises, a característica antropológica de soberania, conferida agora às epistemaï, persiste como uma herança residual de uma antiga tradição exegética em sua argumentação. Este deslocamento da noção de autor para o conceito de episteme não implica a destruição absoluta de todo e qualquer fundamento. O que está em jogo é a desclassificação do sujeito autor em proveito de outro soberano: o conceito de episteme. Eliminando a questão do sujeito ao colocar o pensamento anônimo da episteme em seu lugar, ele nos livra do sujeito, mas não certamente do lugar que ocupara. Não obstante, o que importou notar aqui, livre de todas as polêmicas, foi o uso singular da literatura em As Palavras e as Coisas que testemunha, consoante Foucault, a aglutinação de duas epistémaï em uma mesma obra literária.

\section{Conclusão}

Vimos, portanto, que o estatuto das mudanças repentinas na ordem dos saberes - a irrupção de uma violência exterior e o recurso a um acontecimento selvagem como os únicos a serem capazes de fazer bascular a soberania de uma dada episteme - não permanece tão impensado assim; ainda que velado sob a forma de uma alegorização literária. E não foi por acidente que Foucault escolheu fazer do conceito de acontecimento o centro de suas análises históricas. Este apelo a um evento enigmático na ordem dos saberes possibilitou a Foucault evitar conceitos muito em voga na historiografia tradicional como "influência recíproca" e noções como "continuidade".

Já dissemos, mais acima, que uma das razões para Foucault não fornecer justificativas das passagens entre as epistémaï consistira em que qualquer explicação dada estaria necessariamente incluída em um sistema específico, e datado de pensamento. Permanecíamos, assim, no primeiro nível da articulação dos saberes também chamado de cartográfico. Agora podemos dizer que a utilização foucaultiana da obra Dom Quixote de Cervantes, como articulação do Renascentismo e da Idade Clássica, só foi possível mediante o estatuto residual da obra literária que escapa, assim, à unicidade e à soberania da episteme renascentista para alojar-se na positividade clássica.

Se há algo, portanto, que não pode ser devidamente localizado no interior de uma configuração de saber; devido à sua posição de limite ou borda exterior que ocupa no espaço dos saberes, ao fato de se encontrarem fora da série dos saberes e ao mesmo tempo estarem regularmente inscritas dentro da mesma série; podemos concluir que o papel fundamentador e globalizante que cada episteme exerce perante os demais saberes permanece abalado, devido à capacidade das obras literárias em aglutinarem sucessivamente os deslocamentos entre as epistémaï. Elas contradizem uma 
das características mais fundamentais do conceito de episteme: o estabelecimento das regras do jogo em um dado período constitutivas do espaço no qual todos os saberes são contemporâneos entre si. Foucault advoga estrategicamente a unicidade de cada episteme para argumentar, contra toda a perspectiva anacrônica da história, que um pensador pertencente a sua específica época não poderia ser o precursor ou o sucessor de um saber localizado em outra. Deste modo, a nova configuração de saber não poderá ser entendida como uma herança ou continuação dos saberes formulados anteriormente e dirigidos a um fim que seria o aprofundamento de sua verdade. Afirmar que há ainda alguma relação de etapas, hereditariedade ou tradição na passagem entre duas epistemaï seria permanecer preso dentro dos confinamentos ideológicos de uma história progressiva ou teleológica. A possibilidade de haver qualquer relação entre diversos saberes epistemológicos é descartada, desta maneira, a partir de seu anseio de escrever um novo sistema de periodização da história. Em outras palavras, é nítido que o espírito da arqueologia em As Palavras e as Coisas deseja se opor radicalmente contra toda perspectiva alegórica da história.

Não obstante, pode-se notar, a partir do privilégio concedido a específicas obras literárias, um descompasso entre o espírito e a letra da arqueologia foucaultiana. Pois o papel exercido pela literatura ao alegorizar as profundas acomodações de nosso solo cultural exemplifica a subsunção da "disposição manifesta e contemporânea dos saberes", percorrida pelo arqueólogo, a uma disposição mais fundamental que faz com que o "solo sobre o qual pensamos" não seja o mesmo solo cultural dos clássicos ou renascentistas. A diferença notada entre as ordens dos diversos solos históricos remete-nos, pois, a um segundo nível mais homogêneo dos saberes. Também é preciso não esquecer que, por sua vez, este segundo nível de decalagem da argumentação foucaultiana se desdobra em um terceiro e mais fundamental ainda nível de referência: o chamado fato do "ser bruto da ordem" ou "experiência nua da ordem". E é somente em nome desta experiência ontológica de uma ordem quase transcendental de nosso pensamento que poderemos entrever no percurso arqueológico uma teleologia, ainda que sem relação de continuidade entre as epistemaï, à qual todos os saberes ao longo dos séculos são remetidos. Todas as configurações de saber, desde o século XVI estendendo-se até a episteme moderna, ocupam um mesmo espaço dessa única e soberana episteme sincopada; ora eclipsando, ora manifestando sua transcendência mediante as lacunas abertas entre as diversas modalidades desta ordem. As diferentes epistemaï são, portanto, três regimes de pensamento descontínuos do tempo no interior do campo de uma mesma espacialidade estruturada.

Vimos de abordar a especificidade do estudo foucaultiano da obra de Cervantes articular e relacionar as diferentes configurações de saberes atravessadas por uma descontinuidade. Ao lado do caminho arqueológico que percorre a disposição manifesta dos saberes em sua ordem empírica, 
constata-se uma história literária progressiva que servirá de amparo à história do "retorno da linguagem em seu ser bruto" em nossos dias; pois é a perspectiva de nossa atualidade que determina esta história. A importância das demais referências à literatura, ao longo de As Palavras e as Coisas, revelar-se-á à medida que adentrássemos no estudo da idade moderna; não obstante ela já apareça episodicamente, desde os estudos do século XVI e XVII, mostrando sua relevância: "Dom Quixote é a primeira das obras modernas, pois que aí se vê a razão cruel das identidades e das diferenças desdenhar infinitamente dos signos e das similitudes: pois que aí a linguagem rompe seu velho parentesco com as coisas, para entrar nessa soberania solitária donde só reaparecerá, em seu ser bruto, tornada literatura; pois que aí a semelhança entra numa idade que é, para ela, a da desrazão e da imaginação." (FOUCAULT, 1998; p.63-64 [62]).

Dom Quixote é então um livro onde se exprime a passagem da semelhança à loucura na idade clássica; pois aí a linguagem desaparece ao transformar-se em discurso representativo do real. E é justamente essa redução da linguagem em representação no século XVII correspondente à primeira etapa de uma imensa reorganização da cultura ocidental e responsável pela disposição de nosso saber em que ainda estamos presos que condicionará o aparecimento, em nossos tempos, do que chamamos literatura; responsável agora pela devolução e pelo retorno aos demais saberes discursivos do "ser vivo da linguagem" recoberto pela cultura ocidental desde o século XVI e doravante procurado por Foucault ao longo das páginas de As Palavras e as Coisas.

\section{Referências bibliográficas}

CANGUILHEM, Georges. "Morte de l'homme ou épuisement du Cogito?", Critique, 242, julho de 1967, 32p.

CAPUTO, John. "On not knowing who we are" in Foucault and the Critique of Institutions, The Pensylvania State University Press: University Park, Pensylvania 599p. (1997).

CARROLL, David. The Subject of Archeology or the Sovereignity of the Episteme in Critical Assessements. Vol. II, 149p. (1994).

DELEUZE, Gilles. Conversações, Rio de Janeiro, Editora 34, 226p. (1999). Foucault, São Paulo, Brasiliense, 143p. (2000).

DREYFUS, H. L. \& Rabinow, P. Michel Foucault: um percurso filosófico Rio de Janeiro: Forense Universitária, 319p. (1998)

FLYNN, Thomas R. Foucault's mapping of history in Cambridge Companion to Foucault 360p. (1994)

FOUCAULT, M. A Arqueologia do Saber. Trad. L. F. Baeta Neves. Petrópolis : Vozes, 236p. (1996) . As Palavras e as Coisas. Trad. Salma T. Muchail. São

Paulo : Martins Fontes, 428p. (1998) 
. Les mots et les choses. Paris: Gallimard, 406p (1996).

Linguagem e Literatura Trad. Roberto Machado in Foucault, a filosofia e a literatura Jorge Zahar Rio de Janeiro: 182p. (2000)

. Microfísica do Poder. 8. Ed. Org. e Trad. R. Machado. Rio de Janeiro : Graal, 295p. (1996)

404p. (2003)

Ditos e Escritos I, Rio de Janeiro: Forense Universitária,

392p. (2003)

Ditos e escritos II, Rio de Janeiro: Forense Universitária, . Dits et écrits, Paris, Gallimard, 4301p.

GUTTING, Gary (ed.) The Cambridge Companion to Foucault Cambridge University Press 360p. (1994).

HACKING, Ian. The Archeology of Foucault in Foucault: a critical reader. Cambridge Massachusetts U.S.A, 240p. (1994).

HUPPERT, George. Divinatio et Eruditio: Thoughts on Foucault in Critical Assessements vol II, 149p. (1994).

MACHADO, Roberto. Ciência e Saber - A trajetória da Arqueologia de Foucault. Rio de Janeiro : Graal, 204p. (1994).

Jorge Zahar Ed, 188p. (2000).

MEGILL, Allan. Prophets of Extremity: Nietzsche, Heidegger, Foucault, Derrida, Los Angeles, University of California Press, 399p. (1996).

NUNES, Benedito. A arqueologia da arqueologia in $O$ dorso do tigre, São Paulo: Perspectiva 278p. (1992).

RAJCHMAN, John. Foucault, a liberdade da filosofia. Rio de Janeiro: Jorge Zahar, 288p. (1992).

RIBEIRO, R. Janine (org.). Recordar Foucault. São Paulo : Brasiliense, 249p. (1986).

(1986).

O discurso diferente in Recordar Foucault, 249p.

SMART, Barry. Michel Foucault - Critical Assessments. London and New York, Routledge. 411p. (1994).

VEYNE, P. Foucault revoluciona a História in Como se escreve a História. Brasília : Editora da UNB, 285p. (1990)

WAHL, François. "Há uma episteme estruturalista?" in Estruturalismo e Filosofia, São Paulo: Cultrix. 167p. (1990)

WHITE, Hayden. Foucault Decoded: Notes From Underground in Critical Assessements vol. II, 149p. (1994).

Foucault's Discourse: The Historiography of AntiHumanism in Critical Assessements. vol III, 412p. (1994). 